\title{
Thompson Leads Expanded Executive Committee in 1996
}

\author{
The Materials Research Society Welcomes Two Council Members to the Executive Committee
}

Carl V. Thompson, professor of electronic materials in the Department of Materials Science and Engineering at Massachusetts Institute of Technology, automatically assumes the position of the 1996 Materials Research Society president from his elected office of first vice president in 1995. He succeeds Julia M. Phillips from Sandia National Laboratories who now serves MRS as immediate past president.

The newly elected members of the Executive Committee are Robert Hull (University of Virginia) as First Vice President (President-Elect), Robert J. Nemanich (North Carolina State University) as Second Vice President (Vice President-Elect), and Kevin Jones (University of Florida) as Secretary for a two-year term. A. Kay Hays (Sandia National Laboratories) enters the second year of her two-year term as Treasurer.

In addition, MRS Council has elected two councillors to serve one-year terms on the executive committee: Ronald Gibala (University of Michigan) and Alan I. Taub (Ford Research Laboratory). The Society approved the addition of these representatives to the Executive Committee to share the workload of the Executive Committee and increase council engagement in governance. On a separate ballot, the membership voted to eliminate the position of second vice president, beginning in 1997. This year, before the change takes effect, the second vice president will automatically become vice president in 1997. Until this year, the second vice president was typically elected to the first vice presidential position, thus fulfilling a four-year commitment to the Executive Committee. The change shortens the commitment to three years, beginning with the election of a vice president (president-elect) for 1998.

The newly elected MRS councillors for 1996 are Cammy R. Abernathy, University of Florida; Harry A. Atwater, California Institute of Technology; Martin L. Green, AT\&T Bell Laboratories; Alan J. Hurd, Sandia National Laboratories; Virginia M. Oversby, Lawrence Livermore National Laboratory; Lyle $\mathbf{H}$. Schwartz, National Institute of Standards and Technology; and James S. Williams, Australian National University. They join the following current members of council: Howard K. Birnbaum, University of Illinois-Urbana; Charles B. Duke, Xerox Webster Research Center; Ron Gibala, University of Michigan; James M.E. Harper, IBM T.J. Watson Research Center; Gabrielle G. Long, National Institute of Standards and Technology; Merrilea J. Mayo, Pennsylvania State University; Manfred Rühle, Max-Planck-Institut für Metallforschung; and Alan I. Taub, Ford Research Laboratory.

\section{Carl V. Thompson}

\section{President}

Carl V. Thompson has been a professor of electronic materials in the Department of Materials Science and Engineering at the Massachusetts Institute of Technology (MIT) since 1983. His research interests focus on relationships among processing, structure, properties, and performance of thin films used in electronic devices and circuits and magnetic devices and systems. He and his students have studied modeling of grain growth and recrystallization in semiconductor and metallic films, new thin-film processing techniques, and the effects of microstructure on electromigration in interconnects, contacts, and vias.

Thompson received his MS and PhD degrees in applied physics from Harvard University. During the 1990-91 academic year, he was a U.K. Science and Engineering Research Council visiting fellow at Cambridge University. He has worked briefly for General Electric and U.S. Steel and has consulted for such firms as IBM and Digital Equipment Corporation.

Among his numerous contributions to the Society are serving as second and first vice presidents; symposia organizer; 1990 MRS Spring Meeting Co-chair; and serving on the Continuing Education, Program, and Academic Affairs Committees. Thompson chaired the Audit Committee for two years, and completed a three-year term on Council in 1993.

\section{Robert Hull}

First Vice President (President-Elect)

Robert Hull is an associate professor in the Materials Science and Engineering Department at the University of Virginia. For the past 15 years his research interests covered the areas of superionic conductors, radiation damage mechanisms, ceramic superconductors, metallic superlattices, ion implantation, quantum wires, $x$-ray mirrors, focused ion-beam technologies, and ultrasmall semiconductor particles. He has focused on the fundamental processes of epitaxial growth, defects and degradation mechanisms in electronic materials, the properties of interfaces, and the theory and applications of electron microscopy.

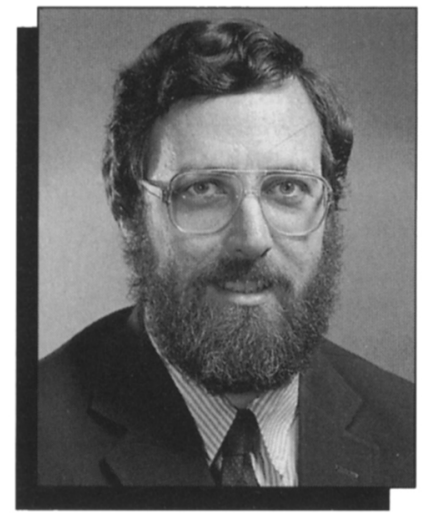

Carl V. Thompson

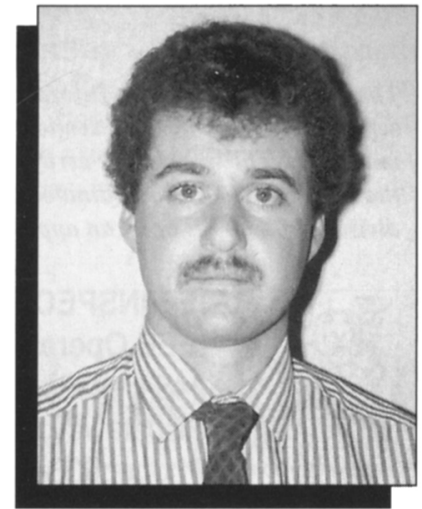

Robert Hull

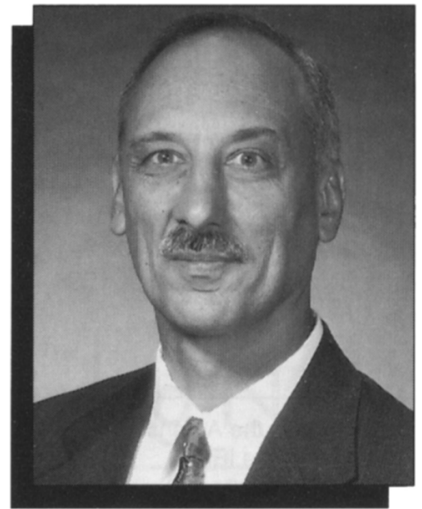

Robert J. Nemanich

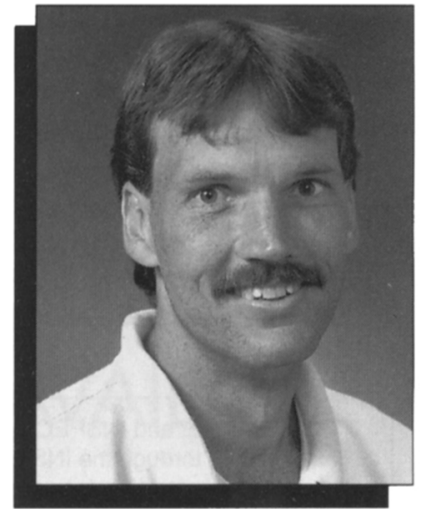

Kevin Jones 
Prior to joining the University of Virginia, Hull worked in the Materials Research Department at AT\&T Bell Laboratories and the Materials Characterization Department at Hewlett Packard Laboratories. Hull received his $\mathrm{PhD}$ degree in materials science from Oxford, England, in 1983.

Along with serving as MRS second vice president, Hull served on Council from 1992 to 1994, and served on the Publications, Program, Academic Affairs, and Continuing Education Committees. He co-chaired three MRS symposia and was a chair for the 1990 MRS Fall Meeting.

\section{Robert J. Nemanich}

Second Vice President

(Vice President-Elect)

Robert J. Nemanich, professor of physics and an associate member of the Department of Materials Science and Engineering at North Carolina State University, coordinates an interdisciplinary research program involving postdoctoral research associates and undergraduate and graduate students from the departments of materials science, physics, and electrical engineering. With his main research interest area in electronic materials, Nemanich's current research topics include diamond and other wide-bandgap semiconductor surfaces and interfaces, heteroepitaxy on $\mathrm{Si}$, semiconductor surface cleaning and preparation, and amorphous and microcrystalline semiconductors.

After receiving his BS degree in physics from Northern Illinois University in 1969 and his $\mathrm{PhD}$ degree in physics from the University of Chicago in 1976, Nemanich worked at Xerox Palo Alto Research Center from 1976 to 1986 . He was involved with research, development, and research management in the Integrated Circuit and General Science Laboratories.
Within MRS, Nemanich served as chair of the Continuing Education Committee for the last three years. Prior to that, he served on the Publications and Program Committees, co-organized five MRS symposia, and co-chaired the 1989 MRS Fall Meeting.

\section{Kevin Jones}

Secretary

Kevin Jones is an associate professor of materials science and engineering at the University of Florida where he directs graduate students investigating microstructural defects which arise from either the growth (metalorganic chemical vapor deposition and metalorganic molecular beam epitaxy) or processing (ion implantation and annealing) of Si, GaAs, GaP, $\mathrm{ZnSe}$, or GaN. With his research interest in the area of processing and characterization of semiconductors, Jones cofounded the FIRST Center (Florida Integrated Research in Silicon Technologies) to assist the silicon integrated circuit industry to better understand and model the effect of processinginduced defects on device properties.

Jones received his MS (1985) and PhD (1987) degrees in materials science and engineering from the University of California-Berkeley. He served as a consultant for several semiconductor processing firms including TRW Inc., Motorola, National Semiconductors, IBIS Technologies, and Kopin Corporation.

Since 1991 Jones has served on the MRS Membership Committee. He has chaired the MRS Academic Affairs Committee since 1993, and has co-organized MRS symposia. Jones has served on MRS Council since 1994.

\section{A. Kay Hays}

Treasurer

A. Kay Hays is manager of the Strategic Planning and Industrial Partnerships
Transition Program Office in the National Security Planning and Operations Center at Sandia National Laboratories where she develops strategic plans for R\&D and industrial partnerships within the National Security business sector at Sandia. Prior to taking this position, Hays developed an industrial partnership program in materials-related technologies for Sandia and managed a variety of research groups in the areas of chemical vapor deposition, physical vapor deposition, plasma deposition, thermal spray, electrochemical deposition, corrosion, and tribology.

Hays received her MS degree in chemistry from the University of CaliforniaBerkeley in 1969 and her PhD degree in physical chemistry from University of California-Los Angeles in 1974.

Within MRS, Hays is continuing her second term as Treasurer. In 1988 she coorganized an MRS symposium and she served as a Meeting Chair for the 1991 Spring Meeting.

\section{Julia M. Phillips}

Immediate Past President

In late 1995, Julia M. Phillips joined Sandia National Laboratories as manager of the Surface/Molecular Spectroscopy Department in the Materials and Process Sciences Center. Prior to that, she spent 14 years at AT\&T Bell Laboratories, most recently supervising the Thin Film Resource Group for seven years.

She received her BS degree in physics from the College of William and Mary in 1976 and her PhD degree in applied physics from Yale University in 1981.

Phillips has served MRS Executive Committee as President (1995), First Vice President (1994), Second Vice President (1993), and Secretary (1987-1989). She has also served as a councillor (1991-1993) and has been an MRS Meeting Chair and sym-

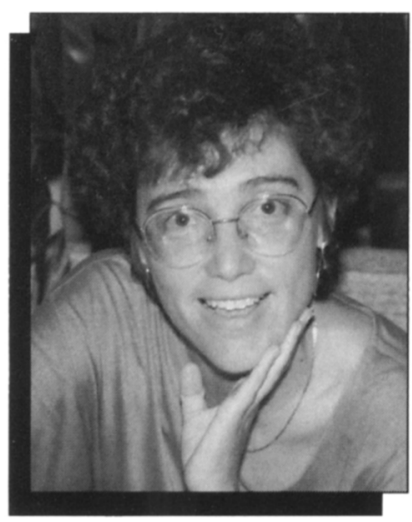

A. Kay Hays

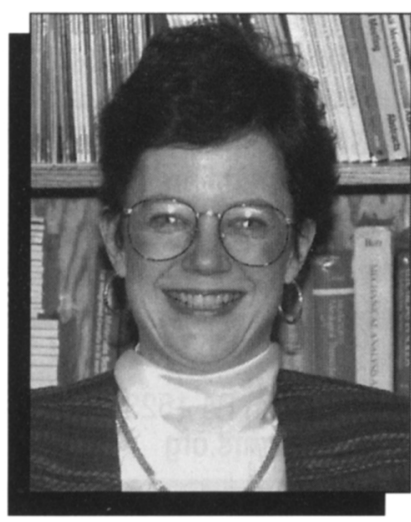

Julia M. Phillips

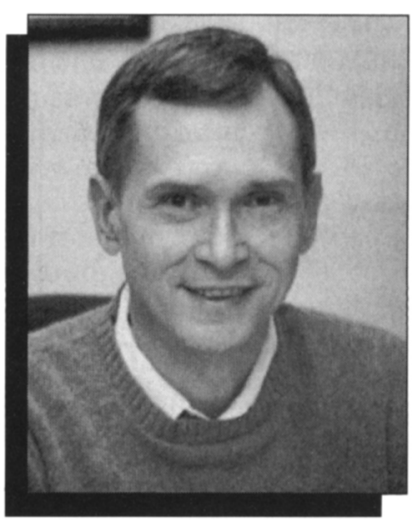

Ronald Gibala

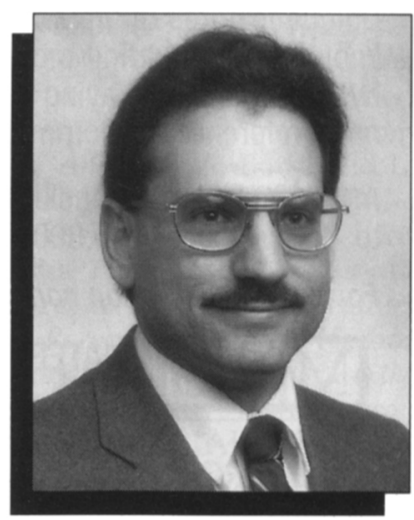

Alan I. Taub 
posium organizer. She has chaired several committees, including the Program, Publicity and Public Relations, and Corporate Participation Committees.

\section{Ronald Gibala}

Councillor

Ronald Gibala is a professor of materials science and engineering in the Department of Materials Science and Engineering at the University of Michigan. He directs the Center for High Temperature Structural Metallic Materials, an interdisciplinary program funded by the Air Force Office of Scientific Research. His current research interests are in the area of mechanical behavior of materials, particularly intermetallic alloys and related quasi-brittle materials.

After receiving his BS degree in metallurgical engineering from CarnegieMellon University (1960) and his MS (1962) and PhD (1964) degrees in metallurgical engineering from the University of Illinois at Urbana-Champaign, Gibala taught at Case Western Reserve University from 1964 to 1984 and was associate director and director of the CWRU Materials Research Laboratory during the latter part of that time. He joined the University of Michigan in 1984.

Gibala has served on numerous advisory committees and participated in various professional societies. In 1988, he co-organized a symposium on science and technology of refractory metals at the MRS Spring Meeting.
Alan I. Taub
Councillor
Alan I. Taub is manager of the Mater- ials Science Department at Ford's Research Laboratory. His research inter- ests have included studies in flow and structural relaxation in amorphous alloys, mechanical properties of rapidly solidi- fied nickel-base alloys with emphasis on improved ductility in intermetallic com-

pounds for aircraft engine applications, and processing of superconducting materials for medical magnets. He currently manages research activities on advanced automobile body, power train, and brake materials.

Taub received his $\mathrm{ScB}$ degree in materials engineering from Brown University in 1976 and his PhD degree in applied physics from Harvard University in 1979. From there he worked with General Electric's Corporate Research and Development Center until 1993. He most recently managed the Materials Properties and Processes Laboratory at GE before joining Ford.

Since joining MRS, Taub has co-organized two symposia on amorphous alloys and high-temperature materials and two on manufacturing, he has co-chaired the 1993 MRS Fall Meeting, and is currently a member of the MRS Award and Public Affairs committees.

\section{Send Lefters to the Editor to: Bulletin@mrs.org}

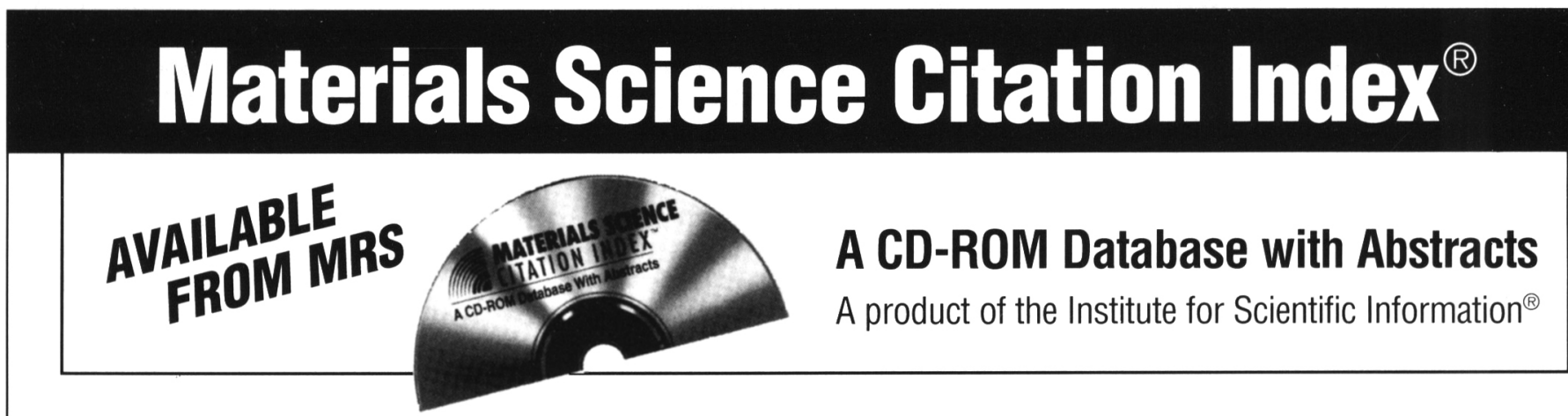

Materials Science Citation Index (MSCI) provides researchers with extensive bibliographic information-including author, title, source publication, author-supplied abstract and cited references-from over 1700 books, journals and conference proceedings related to materials science. Total coverage exceeds 108,500 articles per year. Published bimonthly on compact disc, the Materials Science Citation Index covers all areas of materials science, including ceramics, semiconductors, superconductors, metals and metallurgy, thin films, plastics and polymer engineering, composites, biomaterials, adhesives, minerals, fabrics and fibers...plus electronics, surface science, applied physics, methods of extraction, processing and manufacturing, and more.

Unique features of the $\boldsymbol{M S C I}$ include: searchable author abstracts; cited reference searching, which enables you to take a known paper and find more recent papers that cite it; and Related Records ${ }^{\circledR}$, which extends the power of citation indexing by linking and displaying the articles that have one or more references in common.

A 1996 subscription includes back-year data to 1991 , for over 540,000 source items!

For more information contact:

Code: MSCI-B

$\$ 851.00$ MRS Members U.S. $\$ 871.00$ MRS Members Non-U.S. $\$ 1079.00$ Non-U.S. List

Free Trial Sample Available

\section{$\mathrm{M} \mid \mathrm{R} / \mathrm{S}$}

MATERIALS

RESEARCH

\section{MATERIALS RESEARCH SOCIETY}

Publications Department • 9800 McKnight Road • Pittsburgh, PA 15237-6006

Phone: 412-367-3012• FAX: 412-367-4373•E-mail: info@mrs.org 